\title{
MATERNIDADE E A EVASÃO LABORAL: ALGUNS ASPECTOS DA LICENÇA MATERNIDADE, SALÁRIO MATERNIDADE E AUXÍLIO CRECHE
}

\author{
Juliana Tomiko Ribeiro Aizawa ${ }^{\text {DD }} 1$ e Heloisa Maria de Azevedo ${ }^{\text {DD } 2}$
}

\section{Resumo}

A busca pela paridade laboral de gênero (feminino e masculino) é um desafio permanente e os estudos apontam que a Revolução Industrial foi o marco inicial que reconheceu o trabalho das mulheres fora do ambiente doméstico. Muitas conquistas foram alcançadas por documentos escritos que assegurassem os direitos trabalhistas e previdenciários feminino, no entanto, o período neonatal continua sendo um muro e não uma ponte para muitas trabalhadoras. Ainda que a proteção à maternidade seja um direito fundamental, afirmado no artigo $6^{\circ} \mathrm{da}$ Constituição da República Federativa do Brasil de 1988 (CRFB/88), tornar a maternidade um momento especial na vida da mulher é uma realidade distante, quando se trata de permanência no posto de trabalho. Neste sentido, o presente estudo propõe apresentar os institutos legais nacionais vigentes - salário maternidade e licença maternidade - que asseguram o afastamento laboral das mães por um período determinado com pagamentos de salários. Também aponta quais seriam os benefícios aportados às mães (famílias) se o Projeto de Lei no 3.508/2015 fosse aprovado e instituísse como Lei Ordinária o subsídio disposto em algumas Convenções Coletivas de Trabalho (CCT), caracterizado pelo auxílio-creche.

Palavras-chave: Maternidade; Evação Laboral; Salário maternidade; Licença Maternidade.

\section{MATERNITY AND EMPLOYMENT DEPARTURE: SOME ASPECTS OF MATERNITY LEAVE, SALARY MATERNITY AND DAYCARE ASSISTANCE}

\section{Abstract}

The search for gender labor parity (female and male) is a permanent challenge and studies indicate that the Industrial Revolution was the initial milestone that recognized the work of women outside the home. Many achievements were achieved by written documents that ensured women's labor and social security rights, however, the neonatal period remains a wall and not a bridge for many workers. Although maternity protection is a fundamental right, stated in article 6 of the Constitution of the Federative Republic of Brazil of 1988 (CRFB/88), making maternity a special moment in women's lives is a distant reality when it

\footnotetext{
${ }^{1}$ Mestranda em Fronteiras e Direitos Humanos na UFGD. Professora de prática processual civil do Centro Universitário da Grande Dourados (UNIGRAN).

²Bacharel em Direito pelo Centro Universitário da Grande Dourados (UNIGRAN).
} 
comes to permanence at the workstation. In this sense, this study proposes to present the national legal institutes in force - maternity pay and maternity leave - that ensure the absence of work for mothers for a specified period with salary payments. It also indicates what benefits would be provided to mothers (families) if Bill No. 3.508/2015 were approved and instituted as an Ordinary Law the subsidy provided for in some Collective Labor Agreements (CCT), characterized by daycare assistance.

Keywords: Maternity; labour evasion; maternity salary; maternity leave

\section{Introdução}

O presente estudo visa apresentar os institutos legais nacionais vigentes, como salário maternidade e licença maternidade, que asseguram o afastamento laboral das mães por um período determinado com pagamentos de salários. Para tanto, fazemos a distinção entre licença-maternidade e salário maternidade, bem como o que é o subsídio do auxílio-creche. A análise se norteia tanto pelos desafios impostos pela maternidade, quanto pelo retorno e permanência nos postos de trabalhos.

O gênero priorizado no estudo é o feminino e o problema de pesquisa baseia-se na seguinte indagação: o auxílio creche poderia ser um estímulo como rede de apoio às mulheres após o período da concessão do salário maternidade?

Os marcos teóricos que discorrem sobre direitos fundamentais e relação de trabalho são: Hannah Arendt em " A Condição Humana" e Sérgio Pinto Martins no livro "Direito do Trabalho". Quanto as políticas públicas, dialoga-se com Maria Paula Dallari Bucci e direitos sociais de gêneros através das contribuições de Patrícia Tuma Martins Bertolin.

A fundamentação jurídica nos orienta que com o advento da Consolidação das Leis do Trabalho (CLT) as mulheres passaram a ser juridicamente asseguradas e a partir da Constituição da República Federativa Brasileira de 1988 (CRFB/88) os direitos laborais das gestantes/parturientes foram positivados e equiparados às normas fundamentais. Sendo que um dos principais avanços é garantir as parturientes remunerações mensais, sem trabalho, no período pós-parto.

Deste modo, cumpre nos fazer uma breve distinção dos institutos apresentados no tema deste artigo, qual sejam: salário maternidade, licença maternidade e auxílio creche. O salário maternidade é um direito constitucional e infraconstitucional que concede às puérperas um afastamento das atividades laborais, pelo período de 120 dias, conforme prevê a Lei n. 8.213 de 24 de julho de 1991. A remuneração (benefício) é paga diretamente pelo Instituto Nacional de Seguridade Social (INSS).

A licença maternidade tem a mesma finalidade que o salário maternidade, mas a diferença consiste no pagamento que é feito pelo empregador e depois há a compensação tributária, entre Empresa e União. Já o auxílio-creche é um subsídio a ser prestado por empregadores que contam com 
mais de 30 (trinta) funcionários, a fim de garantir um complemento pecuniário as mães, na importância de $5 \%$ do salário para as lactantes até os 6 meses de vida do bebê, caso a empresa não possua um local adequado para este fim.

Esses institutos, bem como a regulamentação sociojurídica apresentamse nos objetivos específicos, quais sejam, na parte inicial deste artigo discorre sobre a vulnerabilidade social da mulher durante o período pós-parto. $\mathrm{Na}$ segunda parte disserta sobre as dificuldades quanto a paridade da mulher/mãe no meio ambiente de trabalho. Na última parte detalha as informações sobre o salário-maternidade e o projeto de lei que visava o pagamento do auxílio-creche como programa social nacional.

A metodologia utilizada foi a bibliográfica, simples, de cunho exploratório, qualitativa, com buscas em sites jurídicos oficiais, legislação atualizada, leitura de teses, dissertações e artigos científicos, dentro do recorte temporal de 1988 a 2020 e recorte geográfico 4 empresas da cidade de Dourados, Mato Grosso do Sul. Ante essa breve exposição sobre o desenvolvimento da pesquisa, passaremos a análise das fontes.

\title{
2. Maternidade: vulnerabilidade social e precedentes históricos jurídicos
}

\author{
Quem traz no corpo a marca \\ Maria, Maria \\ Mistura a dor e a alegria ${ }^{1}$
}

Iniciamos o estudo contextualizando o Brasil e suas "Marias", a "Maria" que tem contrato laboral ou a que recolhe proventos mensais, ambas terão direito ao seguro social materno. Mas, a "Maria" em um contrato informal de trabalho, não, pois tais benefícios serão prestados apenas àquelas que contribuírem mês a mês junto ao sistema securitário. Aclaramos que, o presente artigo dissertará sobre a trabalhadora empregada que goza de contrato de trabalho formal.

Para tanto é necessário levar em consideração alguns fatos históricos que tiveram forte influência no processo da constituição do saláriomaternidade, como foi a própria Revolução Industrial, a qual dentro de tantos acontecimentos em diversas áreas é considerado um marco histórico para os direitos sociais concedidos às mulheres. Neste período, o trabalho feminino e infantil era considerado como inferior, ao executado pelos trabalhadores de sexo masculino (BARRETO, 2019).

Além disso, a jornada de trabalho tinha uma variação entre 12 (doze) a 16 (dezesseis) horas diárias, sendo que as mulheres recebiam salários menores aos dos homens, em aproximadamente $30 \%$, e, na maioria das vezes exerciam as mesmas atividades dos homens em indústrias têxteis e no setor de mineração, porém não tinham os mesmos direitos (MADALOZZO; MARTINS;

${ }^{1}$ Música “Maria Maria” composta por Milton Nascimentos e Fernando Brant, em 1970. 


\section{SHIRATORI, 2010)}

Embora as mulheres desempenhassem as mesmas funções laborais que os homens, recebiam salários menores, enfrentavam condições de higiene e trabalho precários o que provocava grandes riscos à saúde das mulheres que viviam naquela época. Porém, se sujeitavam as obrigações impostas para não perderam o emprego (SANTOS, 2004; MARTINS, 2012; VIEIRA, 2014).

$\mathrm{E}$ foi a partir desse contexto que surgiram as primeiras preocupações com a proteção da mulher e do infante, surgindo assim as primeiras normas protetivas tanto na Europa, quanto nos demais países ao sul do globo terrestre no período pós-colonial.

Para Bachur e Bachur (2011, p. 21) as mulheres só começam a ser aceitas no mundo do trabalho a partir da Revolução Industrial (1760-1860), deixando de serem vistas apenas como donas de casa, que tinham como funções os afazeres domésticos e passando a serem provedoras do sustento da família junto com seus maridos. Pois, com a Revolução Industrial a mão de obra feminina era utilizada expressivamente nas grandes indústrias que se instalavam no país.

A partir dessas mudanças sociais a proteção à maternidade passou a comportar ao rol de direitos sociais, expressos em Constituições e Acordos Internacionais. As primeiras Constituições que garantiram a tal proteção foram a Mexicana (1917) e Alemã/Weimar (1919), "fala-se em direito à saúde, à moradia, à alimentação, à educação, à previdência etc. Surge um novíssimo ramo do Direito, voltado a compensar, no plano jurídico, o natural desequilíbrio travado, no plano fático, entre o capital e o trabalho" (SARMENTO, 2006, p. 19).

No início do século $X X$, em âmbito internacional, com a instituição da Organização Internacional do Trabalho (OIT) houve a elaboração da Convenção no 04, de 29 de outubro de 1919, a qual é considerada como primeira norma internacional escrita a assegurar direitos e proteção ao trabalho feminino.

A Convenção previa a licença maternidade por um período de 45 dias, antes e depois do parto, sendo o segundo período obrigatório, mediante atestado médico, prevendo a garantia ao emprego, ou seja, a empregada não poderia ser demitida por estar grávida. Esse foi o meio para proteger a mulher durante a gravidez para que não viesse a prejudicar o nascimento do filho (BARROS, 2013).

No ano de 1952 a OIT adotou outra Convenção de suma importância, que foi a de n. ${ }^{\circ} 103$, de 04 de junho de 1952, determinando o artigo 3, inciso 2 uma flexibilização da licença maternidade, sendo previsto que "a duração dessa licença será de doze semanas, no mínimo; uma parte dessa licença será tirada obrigatoriamente depois do parto" (OIT, 1952, s.p).

Além disso o artigo 4, o inciso 8 da Convenção dispôs que "em hipótese alguma, deve o empregador ser tido como pessoalmente responsável pelo custo das prestações devidas às mulheres que ele emprega" (OIT, 1952, s.p). O propósito desta clausula é evitar discriminações de gênero em razão da gravidez, quanto a contratação e os ônus arcados pelo empregador. 
E mais recentemente, a OIT editou a Convenção sobre a proteção da maternidade n.o 183, de 30 de maio de 2000, em seu artigo 4, que ampliou a duração da licença maternidade para 14 (quatorze) semanas, ou seja, 98 (noventa e oito) dias (OIT, 2000). Porém, esta Convenção não foi ratificada pelo Brasil.

No Brasil, segundo Calil (2000), foi a Lei Estadual n. o 1.596, de 29 de dezembro de 1917, do Estado de São Paulo, a primeira norma a concretizar a proteção à gestante, instituindo o Serviço Sanitário Estadual, também previa o não consentimento de labor de mulheres em estabelecimentos industriais no último mês de gravidez, e no primeiro puerpério.

A partir de então, com o surgimento dessas normas de proteção as mulheres grávidas, ficaram evidente que as mesmas necessitavam de cuidados especiais, por parte das empresas, principalmente as tarefas que exigiam maior esforço físico.

Mais tarde outros preceitos foram sendo incorporados aos direitos das mulheres no período da maternidade, tal como o afastamento após o nascimento da criança e garantia à estabilidade laboral. Além disso, quanto o retorno ao trabalho foi assegurado o direito de amamentar o infante, sendo-lhe concedidos intervalos durante o dia para realizar a amamentação (LEGADO BRASIL, 2018).

Destaca-se que, a Constituição da República dos Estados Unidos do Brasil de 1934 foi a primeira a preconizar em seu texto o direito à maternidade. E sucessivamente a Consolidação das Leis do Trabalho (CLT), Decreto no 5.452 de 01 de maior de 1943, com caráter de Lei Ordinária assegurando por um regramento próprio nacional o direito à trabalhadora gestante.

"Com a promulgação da CLT em 1943, determinou-se, no artigo 393 que caberia ao empregador o pagamento dos salários integrais durante as seis semanas anteriores e posteriores ao parto, com base na Constituição de 1937" (PRONI, 2012, p. 43). Este afastamento deveria ser determinado mediante comprovação médica.

E foi com a promulgação da Constituição da República Federativa do Brasil de 1988 (CRFB/88), que houve a equiparação da proteção à maternidade com norma de caráter fundamental, estipulando o tempo de licença à gestante sem prejuízo do emprego e do salário, passando a ter duração de 120 (cento e vinte) dias, de acordo com o que prevê o artigo $7 .{ }^{\circ}$, inciso XVIII.

Art. 70 São direitos dos trabalhadores urbanos e rurais, além de outros que visem à melhoria de sua condição social:

(...)

XVIII - licença à gestante, sem prejuízo do emprego e do salário, com a duração de cento e vinte dias (BRASIL, 1988).

Com essa evolução no ordenamento jurídico houve um aumento de 
políticas públicas ${ }^{1}$ para as trabalhadoras e com o passar dos tempos têm ocorrido diversas mudanças nos direitos sociais relativos as mulheres que trabalham fora do ambiente doméstico.

A partir do marco temporal da CRFB/88 teve um aumento significativo de políticas públicas para as trabalhadoras e o aprimoramento dos direitos sociais relativos às mulheres no mercado de trabalho, muito embora a equiparação laboral quanto ao desenvolvimento da mesma atividade pelo sexo masculino é um estigma social a ser superado.

Outra alteração significativa em favor da maternidade foi a edição da Lei no 10.421/2002, a qual estende a mãe adotiva o direito à licença-maternidade e ao salário maternidade, a paridade está mantida pelas sucessivas alterações na Lei Orgânica da Seguridade Social (LOPS) nº 8.213/91.

A Lei no $11.770 / 2008$ alterou a Lei no 8.212/91 ao criar o Programa Empresa Cidadã destinado à prorrogação da licença-maternidade mediante concessão de incentivo fiscal. Além disso, a Lei no 12.010/2009 acrescentou significativas alterações na CLT quanto a redução da idade para as mulheres gozarem da licença ou salário maternidade.

O legislador inspirou-se mais nas relações domésticas (a mãe também se ocupa da criança adotada) e não na preocupação a respeito da repartição dos papeis familiares, pois se fosse essa a sua intenção, teria estendido também ao pai adotivo a licença obrigatória, que corresponde ao período pós-parto, como, acertadamente, já procedem as legislações dos países escandinavos, da França, da Espanha, de Portugal, da Colômbia, da Venezuela e do Chile, para citar alguns exemplos. O legislador brasileiro poderia ter avançado mais, estendendo a licença também ao pai adotivo (BARROS, 2009, p.1097-1098).

Ante a essa breve análise sobre estes precedentes jurídicos quanto a proteção legal à maternidade discorreremos sobre a mulher gestante no meio ambiente de trabalho.

\section{A discriminação da mulher gestante no meio ambiente de trabalho}

Embora a mulher tenha alcançado seguros sociais vertidos em favor do período puerpério, assim como direitos a igualdade preconizados pela CRFB/88, o tratamento distinto existe nos mais diversos setores, classes e funções principalmente quando se torna "Mãe". Como se a maternidade retirasse as qualidades da mulher excepcional que trabalha, estuda e cuida da casa, para tão somente ser estigmatizada como perfil incompatível ao mercado de trabalho.

As "Marias" que por vezes experimentam o amargor da herança

\footnotetext{
1 "Políticas públicas são programas de ação governamental visando coordenar os meios à disposição do Estado e as atividades privadas, para a realização de objetivos socialmente relevantes e politicamente determinados" (BUCCI, 2002, p. 241).
} 
decolonial, religiosa, patriarcal e discriminatório; de forma tão agressiva sofrem a inoportuna consequência entre a maternidade e o retorno ao posto de trabalho. O que contradiz com as regras sociais, "uma vez que o princípio organizacional deriva claramente do domínio público, e não do privado, a divisão do trabalho é precisamente o que sucede a atividade do trabalho nas condições de domínio público e que jamais poderia ocorrer na privacidade do lar" (ARENDT, 2018, p. 58).

Ademais, de um lado as é fortemente ressaltada a necessidades do infante, o binômio necessidade (afeto e desenvolvimento sociocognitivo) e possibilidade (assistência material), inclusive dispostos nos artigos 1.695 e seguintes do Código Civil de 2002. Por outro lado, o rótulo maternal doméstico obrigatório, por vezes torna inalcançável, conciliar as longas horas da vida laboral fora da privacidade do lar.

Segundo o relatório da Comissão de Igualdade e Direitos Humanos demonstrou que as atitudes negativas em relação a mulheres grávidas e mulheres que retornam da licença de maternidade nas empresas, se deterioraram de forma significativa (ONU/BRASIL, 2018).

O primeiro relatório, mostrou que aproximadamente 54.000 (cinquenta e quatro mil) mulheres em todo o mundo eram forçadas a deixar seus empregos a cada ano, por sofrerem discriminação em razão da gravidez. Essa discriminação não afeta apenas a mulher já em período puerpério, mas também as mulheres em idade fértil, que deixam de planejar e ter filhos pelo medo de perderem o emprego ou o cargo que exercem, além das mulheres com filhos mais velhos que também são afetadas (ONU/BRASIL, 2018).

Além de sofrerem discriminações no ambiente de trabalho, elas também sofrem no ambiente doméstico, pois "pesquisas de abrangência nacional comprovam que o número de horas que as mulheres necessitam empregar para tarefas domésticas, mesmo trabalhando de maneira remunerada, é bastante superior ao dos homens" (SILVA, 2016, p.42).

O que mostra que a mulher em gozo da licença-maternidade, não está apenas recebendo um benefício sem trabalho. Os compromissos domésticos vão muito além de cuidar do filho recém-nascido, porém tal atividade não é reconhecida como trabalho, apenas considerada uma atribuição natural da mulher (KALIL; AGUIAR, 2016).

A pretensa habilidade feminina para as atividades domésticas (o cuidado com a casa e com a família), não obstante seja construída socialmente (as mulheres são condicionadas a isso, há séculos), é naturalizada - e o que é "natural" se reproduz naturalmente ad eternum (BERTOLIN, 2014, p. 37).

Outro fator que deve ser observado é quanto a amamentação, pois as políticas de saúde do Brasil preconizam a defesa da amamentação até o sexto mês de vida do infante. O principal discurso é que além de proteger a saúde do bebê o leite materno também contribui com o orçamento familiar, assim como 
a economia do Estado, pois quando a mulher amamenta o filho evita gastos com leites industrializados, o Estado por sua vez também economiza, pois não precisa fornecer alimentos industrializados para as mulheres de classes sociais menos favorecidas (KALIL; AGUIAR, 2016).

O que se percebe é que o discurso do aleitamento materno não está sincronizado com a legislação trabalhista, que embora tenha assegurado a licença-maternidade, a mesma não alcança os objetivos propostos pelas políticas de amamentação, o que influência as mães abandonarem o aleitamento logo após o final, ou mesmo durante, a licença-maternidade, pois muitas mulheres necessitam muito do emprego, e, entendem que a criança precisa se acostumar a outro tipo de alimentação abandonam o aleitamento antes dos seis meses preconizados pelas políticas públicas de aleitamento do ministério de saúde (KALIL; AGUIAR, 2016). Diante disso, ainda destacam Kalil e Aguiar (2016):

Sobre o abandono da amamentação pelo retorno ao trabalho, parece razoável afirmar que a adoção de novas estratégias de incentivo à amamentação deveria incluir a problematização da questão do trabalho feminino e das políticas familiares, apontando contradições da política de promoção, proteção e apoio à amamentação, que permanecem pouco exploradas nos discursos contemporâneos pró-aleitamento materno. Se a saúde da criança é uma prioridade para o Estado brasileiro e o cuidado com seu desenvolvimento na chamada primeira infância, visto como tão primordial, é tempo de avançar em várias frentes por meio, entre outras coisas, de políticas familiares mais efetivas (KALIL; AGUIAR, 2016, p. 222).

Ficar longe do mercado de trabalho, de acordo com Beltrame e Donelli (2017), mesmo que por curto prazo pode afetar e trazer tensões para a vida da mulher. Por isso muitas mulheres adiam a maternidade, ou deixam de lado o direito de ser mãe, principalmente aquelas que priorizam suas carreiras profissionais, por receio de perderem seus cargos ou postos quando se ausentarem na licença maternidade.

Muitas mulheres ao ficarem afastadas do ambiente de trabalho remunerado, devido a licença maternidade, perdem a chance de serem promovidas, mudar para a gerência ou receber um aumento salarial após o término da licença. Elas também correm maior risco de serem demitidas ou rebaixadas de cargo após a licença maternidade (BELTRAME; DONELLI, 2012).

Esses fatores afetam o psicológico das mulheres, muitas passam o período da licença maternidade preocupadas em como será sua vida profissional ao voltar para o ambiente de trabalho, fatores que acabam prejudicando sua saúde e sua dedicação ao bebê (HIDEG et al., 2018).

Por outro lado, o estudo realizado por Garcia e Viecili (2018) mostra que: 
O retorno ao trabalho após a licença maternidade permite que as mulheres se sintam atuantes, produtivas e em movimento, ampliando seus papéis sociais para além dos papéis de mãe, esposa e cuidadora da casa. Com isso, as mulheres trabalhadoras viabilizam explorar 0 desenvolvimento de competências profissionais, usufruem de reconhecimento social, estabelecem relacionamentos pessoais não restritos à casa e à família, além de alcançar remuneração financeira. Desta forma, pode-se dizer que é possível conciliar estes dois papéis de maneira saudável, desde que a mulher, sua família e a organização em que atua tenham clareza da necessidade de adaptação às novas demandas que irão surgir e dos obstáculos que a mulher precisará superar. Dificuldades sempre existirão, pois é inerente à vida humana. Contudo, é possível às mulheres encontrarem novos arranjos nas suas vidas após o nascimento do bebê e o retorno ao trabalho, estabelecendo limites entre o que a satisfará ou não, entre o que proporciona prazer e desprazer, num exercício constante, visando ao bem-estar individual, familiar e profissional. E esse se torna um desafio constante às trabalhadoras que se tornam mães e aqueles que gerem o trabalho dessas mães trabalhadoras (GARCIA; VIECILI, 2018, p. 278).

Observa-se que, embora seja visível, os desafios em conciliar a carreira profissional bem sucedida com a maternidade, vários autores mostram que é possível harmonizar esta situação e que grande parte das trabalhadoras conseguem conciliar e ter uma vida materna saudável sem afetar a vida profissional, quando constam com redes de apoio ${ }^{1}$.

[...] as redes de apoio são fundamentais para a mulher lidar satisfatoriamente com a maternidade. Nos primeiros meses, 0 suporte fornecido pelas avós e pelos pais proporcionam uma melhor experiência das situações estressantes e permitem que a mulher tenha alguns momentos para cuidar de si (PINTO, 2015, p. 99).

Nesse sentido o trabalho desenvolvido por Alves, Pazello e Scorzafave (2015), ao avaliarem a extensão da licença maternidade, verificaram que esse benefício promoveu um maior engajamento por parte das mulheres no mercado de trabalho que podem conciliar sua vida profissional sem deixar de cumprir seu instinto de maternidade. Por conseguinte, com os direitos garantidos, há a possibilidade de ficar um maior tempo no relacionamento mãe-filho durante o puerpério, desenvolvendo uma tranquilidade psíquica para cuidar do bebê nos primeiros meses de vida sem as preocupações do ambiente profissional.

\footnotetext{
${ }^{1}$ As redes de apoio definidas como escolas, creches, babás, vizinhas e avós. Em cada caso a opção depende do contexto familiar, das crenças compartilhadas pelas famílias (BELTRAME; DONELLI, 2012).
} 
Além disso, as pesquisas mostraram que nesse período, o estresse quanto a insegurança laboral pode desencadear depressão pós-parto. Por tais razões, a extensão da licença maternidade possibilita maior tranquilidade evitando danos à saúde psíquica e o fortalecimento do vínculo filial (GARCIA; VIECILI, 2018).

Depreende-se que, é necessário repensar, também, em políticas públicas que propiciem creches e pré-escolas, visto que a insuficiência desses centros infantis são "um agravante da exclusão da mulher do mercado de trabalho, já que as demandas familiares costumam recair sobre as mulheres, em face da "velha" divisão sexual do trabalho" (BERTOLIN, 2014, p. 37).

Para tanto, nesta oportunidade passaremos a distinguir os institutos salário maternidade, licença maternidade e a possível concessão do auxílio creche.

\section{Salário maternidade, licença maternidade e auxílio creche}

A maternidade é um momento de grande importância na vida mulher e do filho, por isso a legislação vai além da proteção jurídica vislumbrando um caráter social, pois quando protege a mãe trabalhadora, preserva o bem-estar do recém-nascido e da família, repercutindo de forma positiva em toda a sociedade (MEROLA, 2019).

O benefício salário maternidade garante a proteção à trabalhadora gestante, tanto no âmbito do Direito do Trabalho como no Direito Previdenciário, portanto, vale mencionar o conceito de salário-maternidade como um benefício previdenciário pago diretamente pelo INSS à trabalhadora empregada, avulsa, autônoma, empregada doméstica, segurada especial, contribuinte individual, empregada de microempreendedor individual (BRASIL, 2003).

A licença maternidade tem a mesma finalidade que salário maternidade, a diferença consiste quanto ao pagamento da remuneração que é feito diretamente pelo empregador às empregadas/parturientes e depois haverá compensação tributária entre União e Empresa, nos moldes do Art. 248 da CRFB/88 e art. $72, \S 10$ incluso pela Lei no 10.710/2003.

Art. $72 \ldots$

$\S 1^{\circ}$ o Cabe à empresa pagar o salário-maternidade devido à respectiva empregada gestante, efetivando-se a compensação, observado o disposto no art. 248 da Constituição Federal, quando do recolhimento das contribuições incidentes sobre a folha de salários e demais rendimentos pagos ou creditados, a qualquer título, à pessoa física que Ihe preste serviço (BRASIL, 2003).

O valor recebido por estar de licença maternidade é pelo período de 120 (cento e vinte) dias, iniciando-se 28 (vinte o oito) dias antes do parto e findando 91 (noventa e um) dias após. Tais disposições estão expressas no 
artigo 71, da Lei n. 08.213 de 1991, então vejamos:

Art. 71. O salário-maternidade é devido à segurada da Previdência Social, durante 120 (cento e vinte) dias, com início no período entre 28 (vinte e oito) dias antes do parto e a data de ocorrência deste, observadas as situações e condições previstas na legislação no que concerne à proteção à maternidade (BRASIL, LEI 8.213, 1991).

O benefício será devido a todos os segurados que preenchem os quesitos: qualidade de segurado $(a)^{1}$, carência ${ }^{2}$ e comprovar o fato gerador nascimento ou adoção. Como estamos trabalhando com o gênero feminino definiremos as seguradas, que são: trabalhadoras empregadas, avulsas, empregadas domésticas, contribuintes individuais, facultativa, seguradas especiais e desempregadas, desde que estejam dentro de período de graça ${ }^{3}$.

Em determinadas situações, o período anterior ou posterior ao parto ${ }^{4}$ pode ser dilatado por mais duas semanas, mediante comprovação de um atestado médico. Nos casos de aborto não criminoso, a segurada terá direito ao salário-maternidade correspondente a duas semanas.

Com o advento da Lei n¹0.421/2002, o benefício foi ampliado também à segurada que realizasse uma adoção ou obtivesse a guarda judicial para fins de adoção pelo período de 120 dias, se a criança tiver até 1 ano de idade, 60 dias, se a criança tiver entre 1 a 4 anos completos e de 30 dias, a partir dos 4 anos até completar 8 anos.

No entanto, a redação dada pela Lei no $12.873 / 2013$ garantiu o pagamento do salário-maternidade à mãe adotante por 120 dias. Além disso, 0 art. 71-A, §20 da respectiva lei faz a ressalva que "não poderá ser concedido o benefício a mais de um segurado, decorrente do mesmo processo de adoção ou guarda, ainda que os cônjuges ou companheiros estejam submetidos a Regime Próprio de Previdência Social" (BRASIL, 2013).

Nas palavras de Julião (2002, p. 209) a segurada é "a pessoa física que exerce ou exerceu atividade remunerada, constante ou não, habitual ou não, com ou sem vínculo empregatício".

Em relação a carência do salário-maternidade, esta depende da categoria em que a segurada está inserida, pois para as contribuintes individuais, especiais e facultativas são exigidas 10 contribuições mensais para a concessão do benefício as seguradas empregadas, inclusive a doméstica, e

\footnotetext{
${ }^{1}$ A qualidade de segurado(a) está prevista nos artigos 11 ao 15 da Lei no 8.213/91.

${ }^{2}$ A carência do salário maternidade está disposta no artigo 25, II da Lei no 8.213/91.

3 Período de graça é o lapso temporal que o(a) contribuinte mantém a qualidade de segurado(a) independente de contribuições, nos moldes do artigo 15 da Lei no 8.213/91.

${ }^{4}$ Segundo artigo 294, parágrafo $3^{\circ}$ da Instrução Normativa INSS/PRES no 45/10, considera-se parto o evento ocorrido a partir da $23^{a}$ semana ( $6^{\circ}$ mês) de gestação, inclusive em caso de natimorto.
} 
as trabalhadoras avulsas não necessitam da carência (BRASIL, 1991).

Vale ressaltar que, o salário-maternidade não poderá ser acumulado com benefício de incapacidade. As aposentadas que retornarem à atividade terão direito ao benefício, desde que a aposentadoria não seja por incapacidade ou especial. O cálculo para a renda mensal do benefício para segurada empregada ou trabalhadora avulsa será de uma renda mensal igual a sua remuneração integral. Conforme delibera o Art. 73, com redação dada pela Lei no 9.876/1999 e Lei no 10.710/2003, o salário-maternidade terá como remuneração a renda mensal:

Art. 72. O salário-maternidade para a segurada empregada ou trabalhadora avulsa consistirá numa renda mensal igual a sua remuneração integral.

$\cdots$

Art. 73. Assegurado o valor de um salário-mínimo, o saláriomaternidade para as demais seguradas, pago diretamente pela Previdência Social, consistirá:

I - em um valor correspondente ao do seu último salário-decontribuição, para a segurada empregada doméstica;

II - em um doze avos do valor sobre o qual incidiu sua última contribuição anual, para a segurada especial;

III - em um doze avos da soma dos doze últimos salários-decontribuição, apurados em um período não superior a quinze meses, para as demais seguradas (BRASIL, 1999).

Observa-se que a proteção à trabalhadora gestante é garantida, no Brasil, pela Constituição Federal de 1988, tanto na esfera do Direito do Trabalho como do Direito Previdenciário. No que se refere às relações do trabalho, Castro (2008, p. 590) afirma que:

A proteção da gestante se dá: a) pela estabilidade conferida, na forma do art. 10 do Ato das Disposições Constitucionais Transitórias, à empregada urbana ou rural, desde a confirmação da gravidez até cinco meses após o parto, até que venha a ser disciplinada a matéria disposta no inciso I do art. $7^{\circ}$ do Texto Constitucional; b) pela licença-maternidade, de 120 dias, prevista no art. $7^{\circ}$, XVIII; c) pela possibilidade de alteração do local de trabalho ou função, por prescrição médica, a fim de evitar problemas na gestação e pela libertação do trabalho, para fins de consultas médicas e exames, num mínimo de seis vezes, durante o período de gravidez - $\S 4^{\circ}$ do art. 392 da CLT; d) pela autorização legal para rompimento do vínculo de emprego quando prejudicial à gestação, sem que seja devido qualquer desconto ou indenização - art. 394 da CLT; e e) pela vedação expressa à discriminação da mulher no tocante ao seu estado de fertilidade e gravidez, caracterizada a conduta discriminatória do empregador como ilícito penal, além de trabalhista - Lei $n$. $8.213 / 91$. 
É relevante apresentar neste trabalho também, o entendimento jurisprudencial sobre o tempo, pois sabemos que em resumo o salário maternidade foi uma conquista, que teve diversas alterações e elaborações de projetos e leis sobre o mesmo. Contudo é importante salientar de início o entendimento do Supremo Tribunal Federal e o condão de vincular ou ao menos orientar a aplicação do direito no âmbito dos juízes de primeiro grau de jurisdição. Neste sentido, citamos o entendimento da Corte Superior quanto ao prazo, abrangência e finalidade do salário maternidade.

EMENTA DIREITO CONSTITUCIONAL. RECURSO EXTRAORDINÁRIO. REPERCUSSÃO GERAL. EQUIPARAÇÃO DO PRAZO DA LICENÇA-ADOTANTE AO PRAZO DE LICENÇAGESTANTE.

1. A licença maternidade prevista no artigo 70, XVIII, da Constituição abrange tanto a licença gestante quanto a licença adotante, ambas asseguradas pelo prazo mínimo de 120 dias. Interpretação sistemática da Constituição à luz da dignidade da pessoa humana, da igualdade entre filhos biológicos e adotados, da doutrina da proteção integral, do princípio da prioridade e do interesse superior do menor.

2. As crianças adotadas constituem grupo vulnerável e fragilizado. Demandam esforço adicional da família para sua adaptação, para a criação de laços de afeto e para a superação de traumas. Impossibilidade de se thes conferir proteção inferior àquela dispensada aos filhos biológicos, que se encontram em condição menos gravosa. Violação do princípio da proporcionalidade como vedação à proteção deficiente.

3. Quanto mais velha a criança e quanto maior o tempo de internação compulsória em instituições, maior tende a ser a dificuldade de adaptação à família adotiva. Maior é, ainda, a dificuldade de viabilizar sua adoção, já que predomina no imaginário das famílias adotantes o desejo de reproduzir a paternidade biológica e adotar bebês. Impossibilidade de conferir proteção inferior às crianças mais velhas. Violação do princípio da proporcionalidade como vedação à proteção deficiente.

4. Tutela da dignidade e da autonomia da mulher para eleger seus projetos de vida. Dever reforçado do Estado de assegurar-Ihe condições para compatibilizar maternidade e profissão, em especial quando a realização da maternidade ocorre pela via da adoção, possibilitando o resgate da convivência familiar em favor de menor carente. Dívida moral do Estado para com menores vítimas da inepta política estatal de institucionalização precoce. Ônus assumido pelas famílias adotantes, que devem ser encorajadas.

5. Mutação constitucional. Alteração da realidade social e nova compreensão do alcance dos direitos do menor adotado. Avanço do significado atribuído à licença parental e à igualdade entre filhos, previstas na Constituição. Superação de antigo entendimento do STF.

6. Declaração da inconstitucionalidade do art. 210 da Lei no $8.112 / 1990$ e dos parágrafos $1^{\circ}$ e $2^{\circ}$ do artigo $3^{\circ}$ da Resolução 
CJF no 30/2008.

7. Provimento do recurso extraordinário, de forma a deferir à recorrente prazo remanescente de licença parental, a fim de que o tempo total de fruição do benefício, computado o período já gozado, corresponda a 180 dias de afastamento remunerado, correspondentes aos 120 dias de licença previstos no art. 70, XVIII, CF, acrescidos de 60 dias de prorrogação, tal como estabelecido pela legislação em favor da mãe gestante.

8. Tese da repercussão geral: "Os prazos da licença adotante não podem ser inferiores aos prazos da licença gestante, o mesmo valendo para as respectivas prorrogações. Em relação à licença adotante, não é possível fixar prazos diversos em função da idade da criança adotada". (STF, RE 778889, Relator(a): ROBERTO BARROSO, Tribunal Pleno, julgado em 10/03/2016).

Em suma, o salário-maternidade pode ser compreendido como o valor recebido em virtude do nascimento por bebê. Já a licença maternidade é "(...) um período remunerado, destinado ao descanso da mulher trabalhadora, em virtude de nascimento de seu filho ou adoção. Este período é de cento e vinte dias, podendo ser prorrogado em casos excepcionais" (SITESA, 2019, p.2).

A licença maternidade é uma garantia constitucional inserida no artigo 7.0, inciso XVIII da CRFB/88 que dispõe: "são direitos dos trabalhadores urbanos e rurais, além de outros que visem à melhoria de suas condições social: (...) XVIII - licença à gestante, sem prejuízo do emprego e do salário, com a duração de cento e vinte dias". Além disso, o artigo 392 da CLT preceitua que:

Art. 392 A empregada gestante tem direito à licençamaternidade de 120 (cento e vinte) dias, sem prejuízo do emprego e do salário.

$\S 1^{\circ}$ A empregada deve, mediante atestado médico, notificar o seu empregador da data do início do afastamento do emprego, que poderá ocorrer entre o $28^{\circ}$ (vigésimo oitavo) dia antes do parto e ocorrência deste.

$\S .20$ Os períodos de repouso, antes e depois do parto, poderão ser aumentados de 2 (duas) semanas cada um, mediante atestado médico.

$\S .3^{\circ} \mathrm{Em}$ caso de parto antecipado, a mulher terá direito aos 120 (cento e vinte) dias previstos neste artigo.

§. $4^{\circ}$ É garantido à empregada, durante a gravidez, sem prejuízo do salário e demais direitos: I- Transferência de função, quando as condições de saúde o exigir, assegurada à retomada da função anteriormente exercida, logo após o retorno ao trabalho; IIdispensa do horário de trabalho pelo tempo necessário para a realização de, no mínimo, seis consultas médicas e demais exames complementares (BRASIL, CTL, 2002). 
Sendo assim, após o evento parto e consequentemente a licença maternidade, a trabalhadora precisa voltar ao seu emprego, entretanto a CLT em seu artigo 389, parágrafo $1^{\circ}$ estabelece que toda empresa que possua estabelecimento em que trabalharem pelo menos 30 mulheres com mais de 16 anos de idade deverão manter um local apropriado onde seja permitido às empregadas guardar, sob vigilância e assistência, seus filhos no período da amamentação que vai do nascimento aos seis meses do bebê.

Diante disto, em 2015 foi apresentado o Projeto de Lei no 3.508/2015 pelo Deputado Giuseppe Vecci e após a aprovação pela Câmara dos Deputados em 04 de novembro de 2015 foi encaminhado para Plenário as principais alteração previam a inclusão do artigo 400-A à CLT com o seguinte texto:

Art. 400-A. O empregado ou a empregada terá direito ao auxíliocreche para, no máximo, 2 (dois) filhos de até 5 (cinco) anos de idade, por meio de reembolso pelo empregador do valor das despesas com o pagamento de creche.

$\S 1^{\circ} \mathrm{O}$ valor do reembolso de que trata o $\S 1^{\circ}$ deste artigo será de, no mínimo, 5\% (cinco por cento), por filho, do valor do piso salarial da categoria profissional.

$\S 2^{\circ} \mathrm{O}$ auxílio-creche não será devido, cumulativamente, aos pais da mesma criança.

$\S 30$ O empregado deverá comprovar as despesas com o pagamento da creche por meio de recibo que contenha obrigatoriamente o nome completo da criança e de seus pais, com indicação de qual deles é o responsável pelo pagamento.

$\S 4^{\circ}$ As pessoas físicas equiparadas a empregador, as microempresas e as empresas de pequeno porte estão dispensadas do cumprimento do disposto no caput deste artigo.

$\S 50 \mathrm{O}$ valor reembolsado a título de auxílio-creche, correspondente a até $30 \%$ (trinta por cento) do salário do empregado e da empregada:

I - não se incorpora à remuneração para quaisquer efeitos;

II - não constitui base de incidência de contribuição previdenciária ou de depósitos no Fundo de Garantia por Tempo de Serviço;

III - não se configura como rendimento tributável do trabalhador (BRASIL, 2015).

Uma das grandes fundamentações do deputado era "deduzir até cinquenta por cento do valor do auxílio-creche da contribuição devida aos serviços sociais autônomos de natureza social (SESI, SESC, SEST e SENAI)" (BRASIL, 2015). O texto foi indeferido pela Mesa Diretora em 12 de janeiro de 2016, prevalecendo o disposto no artigo 389 , §§ $1^{\circ}$ e $2^{\circ}$ da CLT que diz:

Art. 389 - Toda empresa é obrigada:

$\S 1^{0}$ - Os estabelecimentos em que trabalharem pelo menos 30 (trinta) mulheres com mais de 16 (dezesseis) anos de idade terão local apropriado onde seja permitido às empregadas guardar sob 
vigilância e assistência os seus filhos no período da amamentação.

$\S 20$ - A exigência do $\S 1^{\circ}$ poderá ser suprida por meio de creches distritais mantidas, diretamente ou mediante convênios, com outras entidades públicas ou privadas, pelas próprias empresas, em regime comunitário, ou a cargo do SESI, do SESC, da LBA ou de entidades sindicais (BRASIL, 1943).

O projeto apresentado objetivava maior dinamização orçamentária vertidas ao terceiro setor da administração pública que são: SESI, SENAI, SENAC, SEBRAE, SESC, SEST. Isso porque os valores repassados do capital privado em um serviço público, que é a educação ou a construção de creches comunitárias, na prática não converge com o capital disposto.

Segundo justificativa do Deputado, de janeiro a outubro de 2015 os dados constantes na Receita Federal demonstram que as entidades arrecadaram mais de $\mathrm{R} \$ 6.634 .147 .788,44$ (seis trilhões, seiscentos e trinta e quatro bilhões, centro e quarenta e sete milhões, setecentos e oitenta e oito mil e quarenta e quatro centavos) (BRASIL, 2015).

Dentro do recorte geográfico proposto nesta pesquisa, município de Dourados, estado de Mato Grosso do Sul, foram enviados ofícios para 4 (quatro) grandes empresas, que contam com mais de 30 funcionárias, dos ramos: varejo, alimentos, serviços hospitalares e indústria de embalagens. Os ofícios buscavam uma visão da realidade local do objeto de pesquisa e verificar se havia o pagamento do auxílio-creche.

As tentativas via ofício resultaram sem êxito e ao consultarmos as Convenções Coletivas de Trabalho (CCT) de 2019/2020 das respectivas categorias profissionais verificamos que não há clausula que estipule o pagamento do auxílio creche (BRASIL, MTE, 2020).

Observa-se, por uma pequena análise municipal que o projeto de Lei contemplaria milhares de trabalhadoras que não conseguem vagas em creches públicas e/ou escolas infantis para deixarem seus filhos enquanto trabalham. Evitando, inclusive, a evasão laboral de muitas mães, que por vezes não contam com redes de apoio familiar e sentem-se forçadas a deixar seus postos de trabalho.

Ademais, proporcionar o auxílio-creche como política pública nacional possibilitaria entre outros benefícios uma aproximação entre o empregador e empregada fomentando o desenvolvimento de centros educacionais infantis, garantindo o acesso à educação e permitindo que muitas mulheres continuem sendo as protagonistas de suas próprias vidas.

\section{Considerações finais}

A partir do estudo realizado através da bibliografia selecionada dissertou sobre a vulnerabilidade social das gestantes ao longo do tempo, constatou-se que a Revolução Industrial foi um referencial histórico de mulheres trabalhando 
fora do ambiente doméstico. Porém, há registros nesse período quanto distinção salarial entre trabalhadores e trabalhadoras, longas jornadas laborais e condições de saúde, higiene totalmente inadequadas para mulheres e crianças.

Somente no início do século XX, com a criação da Organização Internacional do Trabalho (OIT) houve a primeira norma internacional que veio proteger as trabalhadoras, assegurando o direito à licença maternidade. Constatou-se ainda que outras normas foram surgindo, com intuito de proteger a trabalhadora empregada no período de gestação.

No Brasil o movimento jurídico escrito mais expressivo foi a Constituição de 1934 e a Consolidação das Leis do Trabalho (CLT), editada em 1943. Instrumentos legais que apresentaram com clareza os direitos das gestantes, garantindo a dispensa das atividades laborais 45 dias antes e 120 dias após o parto. Com a promulgação da CRFB/88 os direitos das mulheres foram fixados com maior ênfase em normas de caráter fundamental, principalmente os direitos a maternidade.

Pode-se observar que o foco na segunda seção do trabalho foram os desafios enfrentados pelas mulheres entre conciliar a vida profissional e a maternidade. Para tanto, alguns pesquisadores afirmam que é possível harmonizar o trabalho e ter uma maternidade saudável, quando as mulheres/mães contam com redes de apoio inclusive com a disposição de creches e redes de educação infantil.

$\mathrm{Na}$ terceira seção deste trabalho a ênfase foi diferenciar o salário maternidade, licença maternidade e o projeto de lei que instituiria o auxílio creche. Nesta parte do artigo observou-se que o salário-maternidade é direito de todas as seguradas, tanto empregadas, avulsas, empregadas domésticas, contribuintes individuais, facultativa, seguradas especiais, adotante e desempregadas, desde que estejam vinculadas ao sistema previdenciário com contribuições mensais.

No que se refere ao auxílio creche, vimos que é um subsídio disposto em Convenções Coletivas de Trabalho (CCT), com o pagamento de no mínimo de cinco por cento do valor do piso salarial da categoria ou conforme convencionado em acordos coletivos.

Em 2015 houve a proposta do projeto de Lei no 3.508/2015, mas em 12/01/2016 foi indeferido pela Mesa Diretora da Câmara dos Deputados. Respectiva Lei previa o pagamento do auxílio creche como uma política pública social integrativa, a qual seria uma alternativa inclusiva e considerada uma forte rede de apoio.

Outrora, os resultados desta pesquisa demonstram que o auxílio creche é pago apenas se houver termo expresso em Convenção Coletiva e dentro do recorte geográfico pesquisado que foi a cidade de Dourados, estado de Mato Grosso do Sul; ao consultar as CCTs observou-se que nenhuma das empresas com mais de 30 funcionárias conta com respectivo subsídio.

Ressalta-se assim como expressiva seria a Lei no 3.508/2015 em favor 
das mães, do bem-estar individual, familiar e profissional. A qual seria mais uma ramificação a fim de oportunizar a tutela e autonomia de muitas mulheres em exercer seus projetos de vida, compatibilizando maternidade e profissão, reparando uma dívida moral e social, principalmente em famílias carentes que não contam com redes de apoio familiar.

Por fim, destacamos que o artigo buscou analisar os institutos já existentes e uma política pública nacional que poderia ser uma ferramenta inclusiva em favor da maternidade e contra a evasão laboral. Porém, é um tema árido e fica à margem de diálogo entre sociedade, estudiosos, pesquisadores, juristas e fomentadores de políticas públicas, para que projetos como o auxílio-creche saiam do papel e permitam, ainda que minimamente, que mulheres/trabalhadoras e mães possam continuar a autoria de suas próprias histórias.

\section{REFERÊNCIAS}

ALVES, Bruna; PAZELLO, Elaine Toldo; SCORZAFAVE, Luiz Guilherme Dácar da Silva. Retorno da mulher ao mercado de trabalho: impacto da licençamaternidade. ANPEC, v. 12, n. 83, 2015. Disponível em: https://www.anpec.org.br/encontro/2017/submissao/files_I/i13a1dce984011249fe59ff408396533c27.pdf Acesso em: 27 set. 2019.

ARENDT, Hannah. A condição humana. 13. ed. Rio de Janeiro: Forense Universitária, 2018.

BACHUR, Tânia Faggioni; BACHUR, Tiago Faggioni. Licença maternidade e salário maternidade: na teoria e na prática. São Paulo: Lemos \& Cruz, 2011.

BARRETO, Gabriella Pereira. A evolução histórica do Direito das mulheres. Disponível em https://gabipbarreto.jusbrasil.com.br/artigos/395863079/a-evolucao-historicado-direito-das-mulheres Acesso em: 16 set. 2019.

BARROS, Alice Monteiro de. Curso de Direito do Trabalho. $4^{a}$ ed, LTR. São Paulo, 2009.

BARROS, Alice Monteiro de. Curso de direito do trabalho. 9. ed. São Paulo: LTr, 2013.

BERTOLIN, Patrícia Tuma Martins. Direito e mudança social: o direito como instrumento para a promoção da igualdade de gênero no Brasil. Revista da Faculdade de Direito da Universidade São Judas Tadeu. no $02.2^{\circ}$ semestre de 2014. p. 33-39. São Paulo - SP. Disponível em: http://www.usjt.br/revistadireito/ Acesso em: 20 set. 2021. 
BELTRAME, Greyce Rocha; DONELLI, Tagma Marina Schneider. Maternidade e carreira: desafios frente à conciliação de papéis. Aletheia, v. 38, n.39, p.206217, maio/dez, 2012. Disponível em:

http://pepsic.bvsalud.org/pdf/aletheia/n38-39/n38-39a17.pdf Acesso em: 14 abr. 2019.

BRASIL. Constituição (1934). Constituição, de 16 de julho de 1934. Constituição da República dos Estados Unidos do Brasil. Brasil, Disponível em:

http://www.planalto.gov.br/ccivil_03/constituicao/constituicao34.htm Acesso em: 17 ago. 2019.

\section{BRASIL. Constituição (1988). Constituição da República Federativa}

Brasileira no 1988, de 05 de outubro de 1988. Brasília, DF, Disponível em: http://www.planalto.gov.br/ccivil_03/Constituicao/Constituicao.htm Acesso em: 11 abr. 2019.

BRASIL. Lei no 5.452, de 01 de maio de 1943. Consolidação das Leis do Trabalho (CLT). Rio Janeiro, Disponível em: https://bit.ly/2QLctw8 Acesso em: 13 abr. 2019.

BRASIL. Lei no 8.212, de 24 de julho de 1991 . Dispõe sobre a Organização da Seguridade Social, institui plano de custeio, e dá outras providências. Brasília, DF. Disponível em: https://bit.ly/2Row6d8. Acesso em: 18 jun. 2019.

BRASIL. Lei no 8.213, de 24 de julho de 1991. Dispõe sobre os Planos de Benefícios daPrevidência Social e dá outras providências. Brasília, DF. Disponível em: https://bit.ly/3b0nz7f Acesso em: 18 jun. 2019.

BRASIL. Decreto no 3.048, de 06 de maio de 1999. Aprova o regulamento da Previdência Social, e dá outras providências. Brasília, DF. Disponível em: https://bit.ly/3vDbmgA Acesso em: 18 jun. 2019.

BRASIL. Lei no 10.421, de 15 de abril de 2002. Estende à mãe adotiva o direito à licença- maternidade e ao salário-maternidade, alterando a Consolidação das Leis do Trabalho, aprovada pelo Decreto-Lei no 5.452, de $1^{0}$ de maio de 1943, e a Lei no 8.213, de 24 de julho de 1991. Brasília, DF. Disponível em: https://bit.ly/3xMKIDJ Acesso em: 18 jun. 2019.

BRASIL. Lei no 10.710, de 05 de agosto de 2003. Altera a Lei no 8.213, de 24 de Julho de 1991, para restabelecer o pagamento, pela empresa, do salário-maternidade devido à segurada empregada gestante. Brasília, DF. Disponível em: <https://bit.ly/3nLfqso>. Acesso em: 05 set. 2019.

BRASIL. Lei no 11.770, de 9 de setembro de 2008. Cria o Programa Empresa Cidadã, destinado à prorrogação da licença-maternidade mediante concessão 
de incentivo fiscal, e altera a Lei no 8.212, de 24 de julho de 1991. Brasília, DF. Disponível em https://bit.ly/3ePYJIp Acesso em: 13 abr. 2019

BRASIL. Lei no 12.2010, de 3 de agosto de 2009. Dispõe sobre adoção; altera as Leis nos 8.069, de 13 de julho de 1990 - Estatuto da Criança e do Adolescente, 8.560, de 29 de dezembro de 1992; revoga dispositivos da Lei no 10.406, de 10 de janeiro de 2002 - Código Civil, e da Consolidação das Leis do Trabalho - CLT, aprovada pelo Decreto-Lei $n^{\circ} 5.452$, de $1^{\circ}$ de maio de 1943; e dá outras providências. Brasília, DF. Disponível em https://bit.ly/3edPcf4 Acesso em: 13 abr. 2019

BRASIL. Instrução Normativa INSS/PRES no 45, de 06 de agosto de 2010. Brasília. DF. Disponível em:

https://www.legisweb.com.br/legislacao/?id=78445 Acesso em: 20 set. 2021.

BRASIL. Supremo Tribunal Federal.Recurso Extraordinario no 778.889. Relator: Ministro Roberto Barroso. Tribunal Pelno. 10 de março de 2016. Publicado em 01 de agosto de 2016. Brasília, DF. Disponível em: https://jurisprudencia.stf.jus.br/pages/search/sjur352981/false Acesso em: 20 set. 2021.

BRASIL. Lei no 12.873, de 24 de outubro de 2013. Altera as Leis no 8.212, de 24 de julho de 1991, e 8.213, de 24 de julho de 1991, o Decreto-Lei no 5.452, de $1^{\circ}$ de maio de 1942 - Consolidação das Leis do Trabalho, as Leis n's 11.491, de 20 de junho de 2007, e 12.512, de 14 de outubro de 2011. Brasília, DF. Disponível em: https://bit.ly/3vHsGRK. Acesso em: 04 ago. 2020.

BRASIL. Projeto de Lei no 3508, de 12 de novembro de 2015. Institui o auxílio-creche, acrescentando artigo à Consolidação das Leis do Trabalho. Brasília, DF Disponível em: https://bit.ly/3ej7pbf Acesso em: 16 ago. 2019.

BRASIL. MINISTÉRIO DO TRABALHO E EMPREGO (MTE). Sistema de negociações Coletivas de Trabalho - MEDIADOR. Disponível em: https://bit.ly/3uineob. Acesso em: 18 nov. 2020.

BUCCI, Maria Paula Dallari. Direito administrativo e políticas públicas. São Paulo: Saraiva, 2002.

CALIL, Léa Elisa Silingowschi. História do direito do trabalho da mulher. São Paulo: LTr, 2000.

CASTRO, Carlos Alberto Pereira de. Manual de direito previdenciário. Florianópolis: Conceito Editorial, 2008. 
GARCIA, Carla Fernandes; VIECILI, Juliane. Implicações do retorno ao trabalho após licença-maternidade na rotina e no trabalho da mulher.

Fractal: Revista de Psicologia, v. 30, n. 2, p. 271-280, maio-ago. 2018. Disponível em:

https://www.scielo.br/j/fractal/a/4zVSP8j3SKn9Rf9TtNvzWzn/?lang=pt\&forma $\mathrm{t}=$ pdf Acesso em: 07 ago. 2019.

HIFEG, Ivone; KRSTIC, Anja; TRAU, Raymond; ZARINA, Tanya. Do Longer Maternity Leaves Hurt Women's Careers?. Harvard Business Review. 14 set. 2018. Disponível em https://hbr.org/2018/09/do-longer-maternity-leaves-hurt-womens-careers Acesso em: 13 out. 2019.

JULIÃo, Pedro Augusto Musa. Curso Básico de Direito Previdenciário. $5^{a}$ ed. Rio de Janeiro: Forense, 2002. Lei n. 10.241, de 15 de abril de 2002.

KALIL, Irene Rocha; AGUIAR, Adriana Cavalcanti de. Trabalho feminino, políticas familiares e discursos pró-aleitamento materno: avanços e desafios à equidade de gênero. Saúde debate, Rio de Janeiro, v. 40, n. 110, p. 208223, jul-set 2016 . Disponível em:

https://www.scielo.br/j/sdeb/a/FMZrcBYBdyBZSxbsvzKXQvS/?lang=pt\&forma $\mathrm{t}=$ pdf Acesso em: 03 set. 2019.

\section{LEGADO BRASIL. Conheça os direitos das mulheres gestantes} no Brasil. Publicado em: 15 agos. 2018, última modificação 15 agosto 2018. Disponível em: https://bit.ly/2Rs9AzZ Acesso em: 03 set. 2019.

MADALOZZO, Regina; MARTINS, Sergio Ricardo; SHIRATORI, Ludmila. Participação no mercado de trabalho e no trabalho doméstico: homens e mulheres têm condições iguais?. Rev. Estud. Fem., Florianópolis, v. 18, n. 2, p. 547-566, Aug. 2010. Disponível em:

https://www.scielo.br/j/ref/a/jshjDy5bBjYS9WxgQMgQT7N/?lang=pt Acesso em: 17 set. 2019.

MARTINS, Sergio Pinto. Direito do Trabalho. 29. ed. São Paulo: Atlas, 2013.

MEROLA, Sérgio. Direitos da mulher: a maternidade e os direitos que a protegem. Disponível em: https://bit.ly/2Rs5o3a Acesso em: out. 2019.

ONUBr, Organização das Nações Unidas no Brasil. Direitos humanos das mulheres. ONUBR. 2018. Disponível em: https://bit.ly/3ehdoNs Acesso em: 02 out. 2019.

OIT. Convenção no C004, de 29 de outubro de 1919. . Washington, Estados Unidos da América. Disponível em: https://bit.ly/3ukqGyj Acesso em: 23 ago. 2019. 
OIT. Convenção no 103, de 04 de junho de 1952. Adotada na $35^{a}$ Sessão da Conferência, em Genebra 1952. Convenção Relativa ao Amparo à Maternidade. Genebra, SUÍÇA, Disponível em: https://bit.ly/3nNuOVh Acesso em: 18 jul. 2019.

OIT. Convenção $\mathbf{n}^{\mathbf{0}} \mathbf{1 8 3}$, de 30 de maio de 2000. Convenção Sobre A Proteção da Maternidade. Genebra, Suíça. Disponível em: https://bit.ly/3nKINw6. Acesso em: 06 jun. 2019.

PAZELO, ElaineToldo. A Maternidade Afeta o Engajamento da Mulher no Mercado de Trabalho? Um Estudo Utilizando o Nascimento de Gêmeos como um Experimento Natural. Estud. Econ., são Paulo, v. 36, n. 3, p. 507-538, julho-setembro 2006. Disponível em:

https://www.scielo.br/j/ee/a/3DSRDHsXczY7DmYzWyGcLpw/?format=pdf\&lan $\mathrm{g}=\mathrm{pt}$ Acesso em: 15 ago. 2019.

PINTO, Fabiane Natalia de Souza. Duas faces da mulher contemporânea: carreira e maternidade. Dissertação de Mestrado. Centro de Teologia e Ciências Humanas da PUC-Rio.

PRONI, Thaíssa Tamarindo da Rocha Weishaupt. Proteção Constitucional à maternidade no Brasil: um caso de expansão da garantia legal. 2012. 116 f. Dissertação (Mestrado) - Curso de Direito, Universidade de São Paulo, São Paulo, 2012. Disponível em: https://bit.ly/3o3LHOf Acesso em: 12 set. 2019.

\section{RECEITA FEDERAL. Repasse da Arrecadação das Outras Entidades e}

Fundos. Brasília: 2019. Disponível em: https://bit.ly/3lmV9c5. Acesso em: 15 set. 2019.

SANTIAGO, Luciano Borges; RICARDINO, Elzimar; VIEIRA, Graciete Oliveira. Direitos da mulher trabalhadora: na gravidez, no pósparto e durante o aleitamento materno. Sociedade Brasileira de Pediatria, 2012. Disponível em:

https://www.sbp.com.br/fileadmin/user_upload/2012/12/Direitos-da-MulherTrabalhadora-na-Gravidez-no-Ps-Parto-e-Durante-o-Aleitamento-Materno.pdf Acesso em: 15 set. 2019.

SANTOS, Josaphá Francisco dos. Manual de direito individual e coletivo do trabalho. 7aed. São Paulo: Atlas, 2004.

SARMENTO, Daniel. Direitos Fundamentais e Relações Privadas. $2^{\mathrm{a}}$ Edição, Rio de Janeiro : Editora Lumen Juris, 2006.

SILVA, Roberta Viegas. Maternidade e mercado de trabalho - avanços possíveis. Boletim Legislativo - Núcleo de Estudos e Pesquisa da Consultoria Legislativa. No 42. Fevereiro/ 2016. Disponível em: 
https://www12.senado.leg.br/publicacoes/estudos-legislativos/tipos-deestudos/boletins-legislativos/bol42 Acesso em: 15 jul. 2019.

SITESA. Licença-maternidade de 120 dias e sua ampliação de prazo aspectos gerais. Disponível em: https://bit.ly/3umky8T Acesso em: 09 set. 2019.

VIEIRA, Regina Stela Corrêa. Saúde e Segurança no Trabalho das

Mulheres: a perspectiva de gênero para a proteção e promoção do meio ambiente laboram equilibrado. 2014. $221 \mathrm{f}$. Dissertação (Mestrado) - Curso de Direito, Universidade de São Paulo, São Paulo, 2014. Disponível em: https://bit.ly/3koGHAZ. Acesso em: 21 set. 2019.

Recebido em: 04 de maio de 2021.

Aceito em: 09 de outubro de 2021. Publicado em: 05 de janeiro de 2022. 